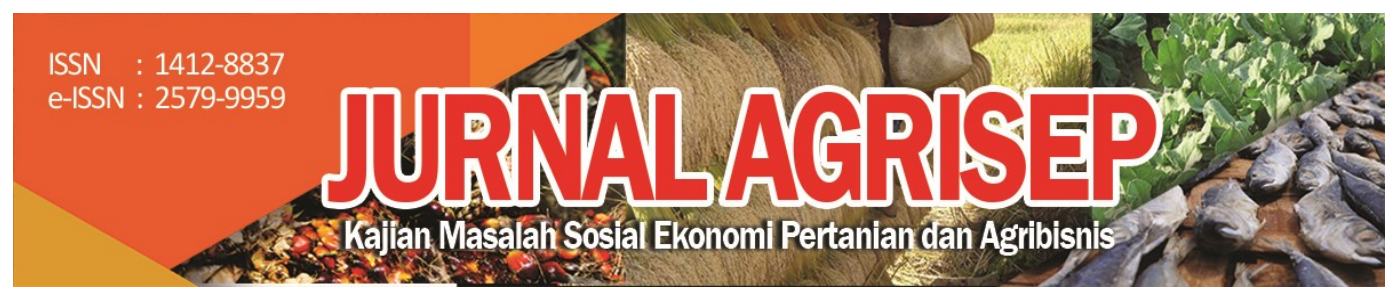

DOI: $10.31186 /$ jagrisep.20.2.279-288

\title{
FAKTOR YANG MEMPENGARUHI MINAT GENERASI MILINEAL UNTUK MENERUSKAN USAHATANI KELUARGA DI KECAMATAN MEJAYAN, KABUPATEN MADIUN
}

\section{Analysis Of Factors Affecting The Interest Of The Milineal Generation To Continue Family Businesses In Mejayan Sub-District, Madiun District}

\author{
Sri Widayanti1) $\bowtie$; Septilia Ratnasari ${ }^{2)}$; Mubarokah ${ }^{3)}$ dan Dita Atasa ${ }^{4}$ \\ 1),2,3),4)Program Studi Agribisnis, Fakultas Pertanian, Universitas Pembangunan \\ Nasional Veteran, Jawa Timur, Indonesia \\ Email: Sriwidayanti@upnjatim.ac.id
}

\begin{abstract}
In the agricultural sector, there was a decrease in the number of young workers, it was noted that in 2018 agricultural workers were dominated by workers aged 40 years and over by 55\%. This is due to the lack of willingness of the younger generation to continue agricultural work as is done by their parents, as well as the unwillingness of parents for their children to do farming activities. The purpose of this study was to analyze the factors that influence the desire of the millennial generation to continue farming activities. The research was conducted in Mejayan Subdistrict by means of multiple stage cluster sampling areas selected Darmorejo village as the criteria for basic agricultural villages, Kaliabu as an industrial village, Mejayan village as a city village. The data analysis used in this research is binary logistic regression with independent variables including gender, motivation, experience, inheritance in the form of land, education, views on agriculture, income, land, community environment. The results showed that the variables that had a positive influence were motivation, inheritance in the form of land, the community environment, while those that had a negative effect were gender and views on agriculture.
\end{abstract}

Keywords : millennial, interests, youth, outlook, agriculture 


\begin{abstract}
ABSTRAK
Pada sektor pertanian terjadi penurunan jumlah tenaga kerja muda, tercatat pada tahun 2018 pekerja pertanian didominasi oleh tenaga kerja yang berumur 40 tahun ke atas sebesar 55\%. Hal tersebut dikarenakan minimnya kemauan generasi muda untuk meneruskan pekerjaan pertanian sebagai halnya yang dilakukan oleh orang tuanya, serta ketidak inginan orang tua untuk anaknya melakukan kegiatan usahatani. Tujuan penelitian ini adalah menganalisis faktor-faktor yang berpengaruh terhadap keinginan generasi milineal dalam meneruskan kegiatan bertani. Penelitian dilakukan di Kecamatan Mejayan dengan cara area cluster sampling multiple stage dipilih desa Darmorejo sebagai kriteria desa basic pertanian, Kaliabu sebagai desa industri, desa Mejayan sebagai desa kota. Analis data yang digunakan pada penelitian ialah regresi logistik biner dengan variabel independen antara lain gender, motivasi, pengalaman, warisan berupa lahan, pendidikan, pandangan terhadap pertanian, pendapatan, lahan, lingkungan masyarakat. Hasil penelitian diperoleh bahwa variabel yang memiliki pengaruh positif ialah motivasi, warisan berupa lahan, lingkungan masyarakat, sedangkan yang berpengaruh negatif ialah gender dan pandangan terhadap pertanian.
\end{abstract}

Kata Kunci : milenial, minat, pemuda, pandangan, pertanian

\title{
PENDAHULUAN
}

Dekade terakhir ini, perubahan sektor ekonomi terjadi begitu cepat, dimana perekonomian bertumpuan utama pada sektor industri dan perdagangan (Oktaviani et al., 2017). Sedangkan, sektor lain terutama pertanian hanya berperan sebagai sektor pendukung. Berubahnya perekenomian nasional berpengaruh juga terhadap perkembangan lahan dan para pekerja (Nugroho et al., 2018). Jumlah pekerja di sektor pertanian yang berlimpah ialah yang berumur di atas 40 tahun atau artinya yang mendominasi ialah mereka yang berumur tua (Deviani et al., 2019). Sedangkan, untuk tenaga kerja dengan umur di bawah 44 tahun jumlah lebih sedikit dibanding tenaga kerja dengan umur lebih dari 45 tahun yang bekerja di sektor pertanian. Pekerja berumur di atas 45 tahun sebanyak 55\%, sedangkan pekerja di bawah 45 tahun sebanyak $45 \%$ ( BPS Madiun, 2019).

Kondisi di wilayah pedesaan sudah menjadi pengetahuan umum bahwa masyarakat desa berumur lebih dari 50 tahun, yang memiliki usahatani merasa bingung memikirkan kelanjutan usahataninya (Ginting \& Sihombing, 2018) (Neonbota \& Kune, 2016). Hal tersebut dikarenakan minimnya kemauan anakanaknya untuk meneruskan pekerjaan tersebut serta ketidak inginan orangtua juga untuk anak mereka melakukan kegiatan pertanian (Sari et al., 2020). Hasil survei menyatakan di negara China, Orangtua yang bekerja di sektor pertanian menginkan anak mereka bekerja sebagai petani. Mayoritas pemuda bermigrasi 
ke kota, dimana $84,5 \%$ diantaranya tidak mengetahui kegiatan pertanian dan 93,6\% menginginkan menetap di kota (Wimatsari et al., 2019).

Masalah tersebut juga terjadi di kecamatan Mejayan, dimana mayoritas orang tua disana tidak berharap anaknya bekerja di sektor pertanian. Hal ini didorong oleh minimnya keinginan generasi milenial disana yang ingin bekerja di sektor pertanian. (Zahara et al., 2013). Dari penjelasan di atas maka dapat ditarik kesimpulan bahwa perlu adanya penelitian tentang faktor apa saja yang berpengaruh terhadap keinginan generasi milenial bekerja di sektor pertanian.

\section{METODE PENELITIAN}

Lokasi penelitian terdapat di desa Darmorejo sebagai desa basic pertanian, desa Kaliabu desa industri, desa Mejayan sebagai desa kota. Proses penentuan jumlah sampel mengunakan metode multistage cluster random sampling (Haq et al., 2018). Masing-masing kriteria diambil 20 sampel sehingga total sampel keseluruhan sebesar 60 sampel yang berusia 20-40 tahun (generasi milineal) (Arvianti,2015). Data didapatkan dari metode wawancara, observasi, dokumentasi, serta literatur terkait. Metode analisis data menggunakan regresi logistik biner. Dimana Model persamaannya yaitu:

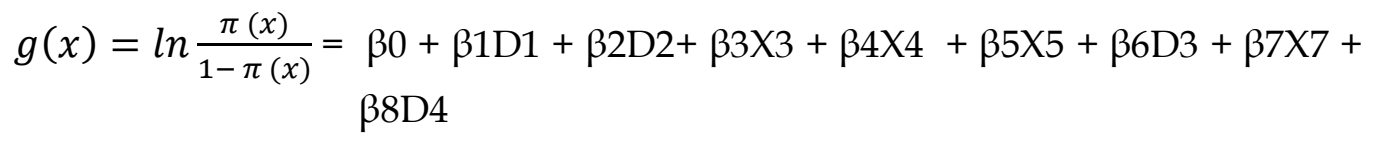

Keterangan :

$\mathrm{g}(\mathrm{x}) \quad$ : minat generasi milineal meneruskan usaha tani keluarga

$\mathrm{G}=1$ untuk berminat tinggi $; 0=$ berminat rendah

$\beta 0 \quad$ : intersep

$\beta 1-\beta 9$ : koefisien regresi

D1 : Jenis kelamin, $1=$ Identik dengan pria $0=$ Tidak idealis satu gender

D2 : Motivasi , 1= Motivasi Tinggi $0=$ Motivasi Rendah

X3 : Pengalaman (tahun)

X4 : Warisan orangtua (hektar)

X5 : Pendidikan (tahun)

D3 : Image negatif pertanian, $1=$ Persepsi Positif $\quad 0=$ Persepsi Negatif

X7 : Pendapatan nonpertanian (rupiah/bulan)

X8 : Kepemilikan lahan (hektar)

D4 : Lingkungan masyarakat, $1=$ Mempengaruhi $0=$ Tidak mempengaruhi

\section{HASIL DAN PEMBAHASAN}

Minat merupakan sudut pandang penghubung antara individu dengan pencahariannya. Kenyamanan serta keinginan terhadap suatu kegiatan tanpa adanya perintah dari siapapun. (Anggraini et al., 2019). Intinya minat dapat 
diartikan sebagai proses suatu ikatan antara individu beserta sesuatu yang berasal dari luar diri (Alitawan \& Sutrisna, 2017). Dimana minat tersebut dapat diukur dengan besar kecilnya hubungan tersebut (Sari et al., 2020). Adapun hasil penilaian minat melanjutkan usahatani keluarga di Kecamatan Mejayan Sebagai Berikut.

Tabel 1. Persentase Minat Generasi Milenial Berdasarkan Jumlah Responden

\begin{tabular}{llll}
\hline No & Minat & Jumlah & Presentase \\
\hline 1 & Minat & 26 & $44 \%$ \\
1 & Tidak Minat & 34 & $56 \%$ \\
& Total & 60 & $100 \%$ \\
\hline
\end{tabular}

Sumber : Data Primer Diolah,2020

Generasi milineal di kecamatan Mejayan rata-rata memutuskan kurang berminat melanjutkan usahatani keluarga dikarenakan tidak adanya wawasan pengetahuan, kurang pengalaman, tidak ada basic mendukung, menganggap pertanian mempunyai resiko berat, pertanian itu pekerjaan yang membuat lelah serta panas, pertanian merupakan pekerjaan musiman, serta sudah memiliki kegiatan di tempat lainnya (Lovitasari \& Diarta, 2017)(Junaedi et al., 2020).

Minat disebabkan oleh beberapa faktor, untuk menganalisis faktor-faktor tersebut digunakan analisis regresi logistic (Muhammad et al., 2016). Analisis regresi logistik adalah alat analisis yang diperuntukkan untuk menerangkan hubugan yang terjadi antara variabel dependen terhadap independen. Uji parameter yang diperlukan dalam regresi logistik adalah uji keseluruhan menggunakan uji likelihood ratio dan uji parsial menggunakan uji Wald (Hartati et al., 2017).

\section{Uji Goodness of Fit (GoF)}

Uji Goodness of Fit adalah uji untuk mengukur keselarasan antar data yang di input pada model beserta data yang diteliti. Menilai kelayakan model (goodness of fit) menggunakan metode Hosmer Lameshow. Hasil Uji GoF dapat telihat dari tabel 1, dimana Uji GoF memperoleh 3,887 untuk nilai chi-square dan 0,867 untuk signifikansinya atau lebih besar dari 0,05, artinya model layak diterapkan dikarenakan tidak ditemukan perbedaan signifikan yang terjadi antara model dan data yang diamati.

Tabel 2. Hasil Uji Goodness of Fit (Gof) Metode Hosmer and Lemeshow Test

\begin{tabular}{ccc|c}
\hline Step & Chi-square & Df & Sig. \\
\hline 1 & 3,887 & 8 &, 867 \\
\hline
\end{tabular}

Sumber: Data Primer Diolah, 2020

Koefisien Determinasi (Nagelkerke R Square) 
Koefisien determinasi berfungsi sebagai indikator dalam mengetahui besar kecilnya variabilitas dari variabel dependen.

Tabel 3. Hasil Koefisien Determinasi (Nagelkerke R Square)

\begin{tabular}{cccc}
\hline Step & -2 Log likelihood & Cox \& Snell R Square & Nagelkerke R Square \\
\hline 1 & $39,027^{a}$ &, 516 &, 690
\end{tabular}

Sumber: Data Primer Diolah, 2020

Dilihat dari Tabel 2 dimana diperoleh nilai 0,690 untuk R2, artinya 69\% variabel independen dapat menjelaskan dependepen (minat) sedangkan 31\% sisanya dapat diterangkan oleh variabel lainnya selaian variabel yang telah ditentukan.

\section{Uji Signifikasi model (Uji G)}

Uji Signifikasi Model berfungsi untuk menguji signifikansi variabel independen secara bersama - sama atau serempak berpengaruh terhadap variabel dependen. Berdasarkan tabel 3 dapat dilihat bahwa nilai signifikasi dari model sebesar 0,000, yang artinya nilai tersebut lebih kecil dibandingkan 0,05. Hal ini memperlihatkan bahwa terjadi penolakan untuk Ho atau secara bersama - sama variabel independen berpengaruh terhadap cariabel dependen atau minat melanjutkan usahatani keluarga .

Tabel 4. Hasil Uji Simultan Variabel (Uji G) Omnibus Tests of Model Coefficients

\begin{tabular}{llccc}
\hline & & Chi-square & Df & Sig. \\
\hline Step 1 & Step & 43,549 & 9 &, 000 \\
& Block & 43,549 & 9 &, 000 \\
& Model & 43,549 & 9 &, 000 \\
\hline
\end{tabular}

Sumber :Data Primer Diolah, 2020

\section{Uji Model secara Parsial}

Bentuk persamaan regresi ialah sebagai berikut :

$$
\begin{aligned}
\mathrm{Y}= & 4,464-2,192 \mathrm{X} 1+4,561 \mathrm{X} 2-0,177 \mathrm{X} 3+1,176 \mathrm{X} 4-0,688 \mathrm{X} 5-1,799 \mathrm{X} 6-0,157 \mathrm{X} 7 \\
& -0,040 \mathrm{X} 8+4,829 \mathrm{X} 9
\end{aligned}
$$

Tabel 5. Hasil Uji Variabel Parsial (Uji Wald)

\begin{tabular}{cccccccc}
\hline & & B & S.E & Wald & Df & Sig. & Exp(B) \\
\hline Step & X1 & $-2,192$ &, 944 & 5,387 & 1 &, 020 &, 112 \\
$1^{\text {a }}$ & X2 & $4,561^{*}$ & 1,675 & 7,413 & 1 &, 006 &, 010 \\
& X3 &,- 177 &, 504 &, 123 & 1 &, 725 &, 838 \\
& X4 & $1,176^{*}$ &, 632 & 3,457 & 1 &, 063 & 3,241 \\
& X5 &,- 688 &, 912 &, 570 & 1 &, 450 &, 502 \\
& X6 & $-1,799$ & 1,072 & 2,818 & 1 &, 093 &, 165 \\
& X7 &,- 157 &, 619 &, 065 & 1 &, 799 &, 854
\end{tabular}




\begin{tabular}{ccccccc} 
X8 &,- 040 &, 437 &, 008 & 1 &, 928 &, 961 \\
X9 & 4,829 & 1,954 & 6,109 & 1 &, 013 &, 008 \\
Constant & 4,464 & 3,441 & 1,683 & 1 &, 195 & 86,804 \\
\hline
\end{tabular}

Sumber: Data Primer Diolah, 2020.

Keterangan :

* = Variabel Independen yang berpengaruh terhadap Variabel dependen

a. Gender

Berdasarkan tabel 4 koefisien variabel gender (X1) sebesar -2,192 dengan besaran signifikasi yaitu 0,020 $(0,020<0,1)$, maka dapat diartikan variabel gender tidak berpengaruh nyata negatif terhadap minat generasi milineal untuk melanjutkan usahatani keluarga di kecamatan Mejayan. Nilai $§$ pada variabel gender yang bertanda negatif menunjukkan bahwa posisi laki - laki dan perempuan belum setara dalam bidang pertanian maka mengakibatkan generasi milineal cenderung tidak berminat untuk melanjutkan usaha tani keluarga.

b. Motivasi

Variabel motivasi (X2) pada tabel 4 memiliki koefisien sebesar 4,561 dan tingkat signifikansi sebesar 0,006 < 0,1 (10\%), artinya variabel motivasi berpengaruh nyata positif pada minat generasi milineal untuk melanjutkan usahatani keluarga di kecamatan Mejayan. Nilai $B$ pada variabel motivasi bertanda positif menunjukkan bahwa semakin besar tingkat motivasi mempengaruhi generasi milineal akan menambah minat untuk melanjutkan usaha tani keluarga. Hasil ini didukung oleh temuan Arimbawa \& Rustariyuni (2018) dimana variabel motivasi memiliki pengaruh terhadap minat anak petani meneruskan usahatani keluarga.

c. Pengalaman

Variabel pengalaman (X3) pada tabel 4 mempunyai nilai koefiien sebesar $-0,177$ dengan nilai signifikasi $0,725>0,1$. Artinya variabel pengalaman tidak berdampak nyata (negatif) pada minat generasi milineal untuk melanjutkan usahatani keluarga di kecamatan Mejayan. Temuan ini selaras pada temuan Effendy et al., (2020) yang menyatakan bahwa pengalaman tidak memiliki pengaruh dalam minat petani untuk berusahata tani.

d. Warisan

Variabel warisan (X4) pada tabel 4 mempunyai nilai koefisien bernilai 1,176 diketahui Nilai signifikansinya 0,063 <0,1 Artinya variabel warisan berdampak nyata pada minat generasi milineal untuk melanjutkan usahatani keluarga di kecamatan Mejayan. Variabel warisan 
diartikan sebagai warisan berupa lahan dari keluarganya. Koefisien pada variabel warisan yang bertanda positif menunjukkan bahwa semakin bertambahnya luas lahan warisan akan mengakibatkan minat generasi milineal untuk melanjutkan usahatani semakin besar. Temuan ini selaras dengan penelitian Nugroho et al., (2018) dimana warisan merupakan salah satu faktor penarik generasi muda untuk terjun ke sektor pertanian.

\section{e. Pendidikan}

Variabel pendidikan (X5) pada tabel 4 mempunyai nilai koefisien 0,688 dan diketahui nilai signifikansinya $0,450>0,1$, artinya variabel pendidikan tidak berdampak nyata pada minat generasi milineal untuk melanjutkan usahtani keluarga di kecamatan Mejayan. Variabel pendidikan memiliki nilai koefisien yang negatif, artinya semakin tinggi tingkat pendidikan, maka generasi milineal akan cenderung tidak berminat untuk melanjutkan usahatani keluarga. Temuan ini selaras dengan penelitian Aryanto \& Sunaryanto (2019) di Kabupaten Wonosobo bahwa pendidikan berpengaruh negatif terhadap minat bertani.

\section{f. Pandangan terhadap Pertanian}

Variabel pandangan terhadap pertanian (X6) pada tabel 4 diketahui nilai koefisien 1,799 dan nilai signifikansinya 0,093<0,1, Artinya variabel pandangan pertanian berdampak nyata pada minat generasi milineal untuk melanjutkan usahtani keluarga di kecamatan Mejayan. Nilai koefisien variabel pandangan pertanian bernilai positif itu artinya bahwa semakin positif persepsi seseorang terhadap pertanian maka akan cenderung lebih berminat untuk melanjutkan usahatani keluarga. Responden pada penelitian ini memiliki persepsi bahwa pertanian pekerjaan berat, merusak penampilan, hasil dari pertanian yang tidak pasti, pekerjaan yang kotor, pertanian dianggap lebih rendah daripada sektor lain, resiko gagal panen karena tergantung pada alam, rugi di biaya, pendapatan dan penghasilan tidak seimbang.

g. Pendapatan di Luar Sektor Pertanian

Pendapatan di penelitian ini yang dimaksud ialah pendapatan yang berasal dari luar sektor pertanian. Variabel pendapatan (X7) pada tabel 4 diketahui nilai koefisien -0,157 dan nilai signifikansinya 0,799>0,1, Artinya variabel pendapatan tidak berdampak nyata pada minat generasi milineal untuk melanjutkan usahtani keluarga di kecamatan Mejayan. Nilai negatif pada koefisien variabel pendapatan berarti semakin besar pendapatan di sektor lain maka tidak akan cenderung berminat untuk melanjutkan usahatani. 
h. Lahan

Variabel lahan (X8) pada tabel 4 diketahui nilai koefisiennya $-0,40$ dan nilai signifikansinya $0,928>0,1$, Artinya bahwa variabel lahan tidak berdampak nyata pada minat generasi milineal untuk melanjutkan usaha tani keluarga di kecamatan Mejayan. Temuan ini tidak selaras dengan Marza et al., (2020) dimana luas lahan berdampak nyata pada minat generasi milenial untuk meneruskan usahatani keluarga. Perbedaan hasil ini dapat dijelaskan meskipun keluarga tani di Kecamatan Mejayan memiliki lahan yang luas, mereka cenderung tidak menginginkan anaknya untuk bekerja dalam sektor pertanian, lahan yang dimiliki bisa di garap orang lain atau di alih fungsikan ke sektor yang lain.

i. $\quad$ Lingkungan Masyarakat

Variabel image (X9) pada tabel 4 diketahui nilai koefisiennya 4,829 dan nilai signifikansinya $0,013<0,1$, Artinya variabel lingkungan masyarakat berdampak nyata pada minat generasi milineal untuk melanjutkan usahatani keluarga di kecamatan Mejayan. Nilai positif pada koefisien variabel lingkungan masyarakat berarti semakin mendukungnya lingkungan masyarakat maka kecenderungan minat untuk melanjutkan usahatani keluarga semakin besar.

\section{SIMPULAN DAN SARAN}

\section{Simpulan}

Kesimpulann yang dapat diambil dalam penelitian ini adalah bahwa faktor yang mempengaruhi generasi milineal untuk melanjutkan usahatani keluarga di Kecamatan Mejayan secara parsial ialah variabel gender berpengaruh negatif, variabel motivasi berpengaruh positif, variabel warisan berpengaruh positif, variabel pandangan terhadap pertanian berpengaruh negatif serta variabel lingkungan masyarakat berpengaruh positif. Sedangkan variabel yang tidak berpengaruh ialah pengalaman, pendidikan, pendapatan, dan lahan

\section{Saran}

Berdasarkan hasil di atas responden masih memiliki pandangan yang negatif maka perlu mewujudkan pertanian kearah lebih modern hal itu bisa dimulai dari pemerintah menerapkan kebijakan-kebijakan yang sudah dibuat lebih menyeluruh lagi sehingga mampu merubah mindset generasi milenial terjun ke dunia pertanian dan menciptakan pertanian kesejateraan di tingkat petani. 


\section{DAFTAR PUSTAKA}

Alitawan, A. A. I., \& Sutrisna, I. K. 2017. Faktor-Faktor yang Mempengaruhi Pendapatan Petani Jeruk pada Desa Gunung Bau Kecamatan Kintamani Kabupaten Bangli. E-Jurnal Ekonomi Pembangunan Universitas Udayana. 6(5): 796-826.

Anggraini, R., Arida, A., \& Hakim, L. 2019. Faktor-Faktor yang Mempengaruhi Minat Petani terhadap Usahatani Nilam di Kabupaten Aceh Jaya. Jurnal Ilmiah Mahasiswa Pertanian Unsyiah. 4(1): 337-347.

Arimbawa, I. P. E., \& Rustariyuni, S. D. (2018). Respon Anak Petani Meneruskan Usaha Tani Keluarga di Kecamatan Abiansemal. E-Jurnal EP Unud. 7(7): 1558-1586.

Aryanto, L. D., \& Sunaryanto, L. T. 2019. Faktor - Faktor yang Mempengaruhi Minat Petani Bekerja di Luar Sektor Pertanian di Desa Besuki, Kecamatan Wadaslintang, Kabupaten Wonosobo. Jurnal Pertanian Terpadu. 7(2): 131-140.

Badan Pusat Statistik. 2019. Kabupaten Madiun Dalam Angka 2019. Kabupaten Madiun: BPS.

Deviani, F., Rochdiani, D., \& Saefudin, B. R. 2019. Analisis Faktor-Faktor yang Mempengaruhi Produksi Usahatani Buncis di Gabungan Kelompok Tani Lembang Agri Kabupaten Bandung Barat. Agrisocionomics: Jurnal Sosial Ekonomi Pertanian. 3(2): 165-173.

Effendy, L., Maryani, A., \& Azie, A. Y. 2020. Faktor-Faktor yang Mempengaruhi Minat Pemuda Perdesaan pada Pertanian di Kecamatan Sindangkasih Ciamis Factors Affecting Rural Youth Interest in Agriculture in Sindangkasih Ciamis District. Jurnal Penyuluhan. 16(2): 277-288.

Ginting, N. E., \& Sihombing, D. 2018. Analisis Faktor - Faktor yang Mempengaruhi Minat Petani Berusahatani Jagung di Desa Mardingding. JURNAL PLANS - Penelitian Ilmu Manajemen Dan Bisnis. 13(2): 77-81.

Haq, A., Pata, A., \& Sadat, M. A. 2018. Faktor-Faktor yang Mempengaruhi Minat Petani dalam Budidaya Cabai Besar di Desa Pattiro Deceng, Kecamatan Camba, Kabupaten Maros. Jurnal Agribisnis. 7(1): 1-13.

Hartati, G. A. R., Budhi, M. K. S., \& Yuliarmi, N. N. 2017. Analisis Faktor-faktor yang Mempengaruhi Kesejahteraan Petani di Kota Denpasar. E-Jurnal Ekonomi Dan Bisnis. 6(4): 1513-1546.

Junaedi, A. J., Anwarudin, O., \& Makhmudi, M. 2020. Dinamika Kelompok Tani Terhadap Minat Generasi Muda Pada Kegiatan Usahatani Padi di Kecamatan Gantar Kabupaten Indramayu. Jurnal Inovasi Penelitian. 1(3): 501-512. 
Lovitasari, N. M., \& Diarta, I. K. S. 2017. Persepsi Generasi Muda terhadap Minat Bertani di Kawasan Pariwisata Tanah Lot (Kasus Subak Gadon III, Tabanan). Jurnal Agribisnis dan Agrowisata. 6(4): 477-485.

Marza, A. R., Ismono, R. H., \& Kasymir, E. 2020. Faktor - Faktor Yang Mempengaruhi Minat Pemuda Pedesaan Dalam Melanjutkan Usahatani Padi Di Kabupaten Lampung Tengah. JIIA. 8(1): 48-54.

Muhammad, A., Agustono, A., \& Wijianto, A. 2016. Faktor-Faktor Yang Mempengaruhi Minat Petani Dalam Berusahatani Padi Di Kecamatan Kebakkramat Kabupaten Karanganyar. SEPA: Jurnal Sosial Ekonomi Pertanian Dan Agribisnis. 12(2): 205-213.

Neonbota, S. L., \& Kune, S. J. 2016. Faktor-Faktor yang Mempengaruhi Usahatani Padi Sawah di Desa Haekto, Kecamatan Noemuti Timur. Jurnal Agrimor. 1(03): 32-35.

Nugroho, A. D., Waluyati, L. R., \& Jamhari. 2018. Upaya Memikat Generasi Muda Bekerja pada Sektor Pertanian di Daerah Istimewa Yogyakarta. Jurnal Ilmu Pemerintahan Dan Sosial Politik UMA. 6(1): 76-95.

Oktaviani, L., Usman, M., \& Azhar, A. 2017. Analisis Pandapatan dan FaktorFaktor yang Mempengaruhi Minat Petani Terhadap Usahatani Padi Sawah di Kecamatan Meureubo Kabupaten Aceh Barat. Jurnal Ilmiah Mahasiswa Pertanian. 2(1): 191-199.

Sari, A. P., Ismono, R. H., \& Adawiyah, R. 2020. Analisis Pendapatan, Persepsi, Dan Minat Petani Dalam Berusahatani Ubi Kayu Di Kecamatan Sukadana Kabupaten Lampung Timur. JIIA. 8(3): 474-481.

Wimatsari, A. D., S. S. Hariadi, \& E. Martono. 2019. Youth Of Village Attitudes On Organic Farming Of Snakefruit And It's Effect Toward Their Interest On Farming Organic. Journal of Agribusiness and Rural Development Research. 5(1): 55-65.

Zahara, Pujiharti, Y., \& Silalahi, M. 2013. Proses Pengambilan Keputusan dan Faktor-Faktor yang Mempengaruhi Minat Petani Terhadap Penggunaan Varietas Unggul Padi Di Kabupaten Lampung Selatan. Prosiding Seminar Nasional Agroinovasi. 375-389. 